\title{
The role of prolyl oligopeptidase, understanding the puzzle
}

\section{J. Arturo García-Horsman}

Division of Pharmacology and Pharmacotherapy, Faculty of Pharmacy, Helsinki, Finland

Correspondence to: J. Arturo García-Horsman. Division of Pharmacology and Pharmacotherapy, Faculty of Pharmacy, Viikinkaari 5E, Helsinki 00790, Finland. Email: arturo.garcia@helsinki.fi.

Provenance and Peer Review: This article was commissioned by the editorial office, Annals of Translational Medicine. The article did not undergo external peer review.

Comment on: Jiang DX, Zhang JB, Li MT, et al. Prolyl endopeptidase gene disruption attenuates high fat diet-induced nonalcoholic fatty liver disease in mice by improving hepatic steatosis and inflammation. Ann Transl Med 2020;8:218.

Submitted Apr 18, 2020. Accepted for publication Apr 28, 2020.

doi: $10.21037 / \mathrm{atm}-20-3412$

View this article at: http://dx.doi.org/10.21037/atm-20-3412

Prolyl oligopeptidase or prolyl endopeptidase (POP or PREP) was first described 50 years ago as an oxytocin cleaving enzyme (1) and it was further characterized as a peptidase able to cleave short peptides at the $\mathrm{C}$-side of an internal proline (2). Because of its specificity, and the occurrence of internal proline residues in several neuropeptides, PREP was soon regarded as a peptidase relevant in neuropeptide metabolism, with a great drug target potential for neurological disorders' therapy (3). Accordingly, synthesis and testing of PREP inhibitors became the attention of academia and industry, especially since evidence emerged that PREP inhibition improved cognitive decline and dementia in several animal models [reviewed in (4)]. Some of the very potent and specific inhibitors were taken to preclinical/clinical trials (5). The impetus started to fade away when further research determined that the role of PREP, as neuropeptide regulator, was not that clear. The hypotheses to support its role in learning and memory were not solid enough (6). One of the main concerns was the notion that PREP was considered intracellular and mainly expressed within neurons. This idea seemed to be contradictory with the extracellular environment of bioactive peptide regulation, where the receptor-neuropeptide interaction takes place. Furthermore, additional evidence pointed out that PREP was present in almost all tissues, at significant levels, and not just within the cytoplasm, but within neuron nuclei, attached to membranes, and extracellularly [see for example (7) and papers therein]. This, along with the poor information on the role of PREP in any of those locations, ceased the interest of pharmaceutical industry to continue the efforts to validate PREP for clinical treatment of dementia.

Only few laboratories had been working to try to unveil the role of PREP in the body (2-4,6-8), and this task has not been easy. During more than 20 years, experimental work has indicated that probably PREP has not one physiological unique distinctive role, but many, which depend on the milieu PREP is located: in or out of the cell, the type of cell or tissue, or the metabolic or pathological conditions in cells, tissues or whole organism. These roles could be also determined by the kind of interaction with physiological peptides (cleavage substrates or inhibitors) or with other protein partners (8).

Information about involvement of PREP in processes non-dependent of its peptidase activity have been substantiated. Genetically or biochemically inactivated versions of this peptidase are able to participate in neuron growth cone, decrease of alpha-synuclein deposits, and other interactions with key proteins as GAP43, tubulins, etc. (8).

As a peptidase, PREP seems to have a clear role on peptide regulation in the renin-angiotensin system, participating in processing angiotensin II (9). On the other hand, there is evidence that PREP is also involved in the digestion of thymosin $\beta 4$ to generate the tetrapeptide AcSDKP, which promotes angiogenesis, reduces fibrosis and apoptosis, and has anti-inflammatory effects (10).

In brain, the evidence of PREP participating in neuropeptide metabolism has not been conclusive (8). 
However, changes of PREP activity have been found in pathologies where neuroinflammation has a central role, as multiple sclerosis, cirrhosis, depression, neurodegeneration and cancer (11-14). Indeed, it has been shown that PREP is secreted by immunoactivity cells $(15,16)$, this being obnoxious to the close parenchymal cell population. However, the molecular mechanisms involved in this activity have not been substantiated. The peptide PGP has been described to correlate with PREP levels in inflammatory lung diseases as chronic obstructive pulmonary disease, and cystic fibrosis (11), by activating neutrophils thorough CXC receptors.

In previous in vitro studies Zhou et al., showed that PREP increases upon hepatocyte steatosis and that PREP inhibitors reduce lipid accumulation (17). In their report, Jiang et al. (18), hypothesized that PREP disruption would ameliorate disorders of lipid metabolism and hepatic inflammation to prevent nonalcoholic fatty liver disease (NAFLD) progression to nonalcoholic steatohepatitis (NASH). This work indeed shows that PREP disruption reduces visceral adipose tissue, downregulates free fatty acid transporters, and improves de novo lipogenesis in steatohepatitis mouse model. Authors, in part, relate these findings to previous reports on changes in mitochondrial protein turnover due to PREP inhibition (19), but also invoke to a possible gene expression control mediated by this peptidase (20), through a mechanism which involves PPAR- $\gamma$ expression modulation, a key gene in the regulation of lipid metabolism.

The other important finding of this study, represents the observation that the lack of PREP decreased considerably the inflammatory response produced by high fat diet in wild type animals. Certainly, alteration of inflammatory response has been reported in the brain from mice in PREP-knockout mice in our laboratory (21). Jiang et al. (18) find that the hepatic macrophage population, as well as PGP peptide levels, are decreased in high-fat diet (HFD) PREP-deficient mice. As mentioned above, PGP peptide and its $\mathrm{N}$-acetylated derivative are strong neutrophil activators. This peptide is derived from the degradation of the extracellular matrix (ECM) collagen by a concerted action of metalloproteinases and PREP. Thus, the lack of PREP, and the decreased expression of metalloproteins, observed in the PREP deficient mice in this study, are then culprit for the fall in neutrophils activation in the steatosis model. Furthermore, the receptor of this peptide (CXCR2) was found also increased at some extent in the HFD wild type mice, compared with those levels in the liver of lowfat diet (LFD) animals from the same genotype. However, those levels were found decreased in the liver of both dietary conditions in the PREP-deficient mice, especially on HFD mice. Accordingly, Jiang et al. (18) proposed that PREP disruption inhibits the accumulation of hepatic macrophages by regulating the generation of PGP (Ac-PGP) and neutrophil chemotaxis upon HFD stimulus. Finding whether the reduction on inflammatory response is due directly to PREP absence itself, or to the lower hepatic fat accumulation in these mice, would be a further hypothesis for a follow-up research.

ECM remodeling has multiple participation on disease (22), Previous research has showed that ECM digestion by physiological proteases and peptidases, lead to the formation of "matrikines", which are capable to regulate inflammatory cell phenotypes both in vitro and in vivo (23). In the commented article (18), and in previous research (17), Jiang et al. provide evidence that PREP is indeed having a central part in the relation of ECM remodeling, and thus, in inflammation, paving the road ahead in the research of this interesting protein.

\section{Acknowledgments}

I deeply thank the Division of Pharmacology and Pharmacotherapy, and the Faculty of Pharmacy, University of Helsinki for having provided the opportunity to write this manuscript.

Funding: None.

\section{Footnote}

Conflicts of Interest: The author has completed the ICMJE uniform disclosure form (available at http://dx.doi. org/10.21037/atm-20-3412). The author has no conflicts of interest to declare.

Ethical Statement: The author is accountable for all aspects of the work in ensuring that questions related to the accuracy or integrity of any part of the work are appropriately investigated and resolved.

Open Access Statement: This is an Open Access article distributed in accordance with the Creative Commons Attribution-NonCommercial-NoDerivs 4.0 International License (CC BY-NC-ND 4.0), which permits the noncommercial replication and distribution of the article with the strict proviso that no changes or edits are made and the original work is properly cited (including links to both the 
formal publication through the relevant DOI and the license). See: https://creativecommons.org/licenses/by-nc-nd/4.0/.

\section{References}

1. Walter R, Shlank H, Glass JD, et al. Leucylglycinamide released from oxytocin by human uterine enzyme. Science 1971;173:827-9.

2. Szeltner Z, Polgar L. Structure, function and biological relevance of prolyl oligopeptidase. Curr Protein Pept Sci 2008;9:96-107.

3. García-Horsman JA, Männistö PT, Venäläinen JI. On the role of prolyl oligopeptidase in health and disease. Neuropeptides 2007;41:1-24.

4. Männisto PT, Venäläinen J, Jalkanen A, et al. Prolyl oligopeptidase: a potential target for the treatment of cognitive disorders. Drug News Perspect 2007;20:293-305.

5. Morain P, Lestage P, De Nanteuil G, et al. S 17092: a prolyl endopeptidase inhibitor as a potential therapeutic drug for memory impairment. Preclinical and clinical studies". CNS Drug Rev 2002;8:31-52.

6. Lambeir AM. Translational research on prolyl oligopeptidase inhibitors: the long road ahead. Expert Opin Ther Pat 2011;21:977-81.

7. García-Horsman JA. Prolyl oligopeptidase in Brain Function and Dysfunction. CNS Neurol Disord Drug Targets 2011;10:296.

8. Männistö PT, García-Horsman JA. Mechanism of Action of Prolyl Oligopeptidase (PREP) in Degenerative Brain Diseases: Has Peptidase Activity Only a Modulatory Role on the Interactions of PREP with Proteins? Front Aging Neurosci 2017;9:27.

9. Serfozo P, Wysocki J, Gulua G, et al. Ang II (Angiotensin II) Conversion to Angiotensin-(1-7) in the Circulation Is POP (Prolyloligopeptidase)-Dependent and ACE2 (Angiotensin-Converting Enzyme 2)-Independent. Hypertension 2020;75:173-82.

10. Kumar N, Yin C. The anti-inflammatory peptide AcSDKP: Synthesis, role in ACE inhibition, and its therapeutic potential in hypertension and cardiovascular diseases. Pharmacol Res 2018;134:268-79.

11. Penttinen A, Tenorio-Laranga J, Siikanen A, et al. Prolyl oligopeptidase: a rising star on the stage of neuroinflammation research. CNS Neurol. Disord. Drug Targets 2011;10:340-8.

12. Tenorio-Laranga J, Peltonen I, Keskitalo S, et al. Alteration of prolyl oligopeptidase and activated $\alpha-2$ macroglobulin in multiple sclerosis subtypes and in the clinically isolated syndrome. Biochem Pharmacol 2013;85:1783-94.

13. Tenorio-Laranga J, Montoliu C, Urios A, et al. The expression levels of prolyl oligopeptidase responds not only to neuroinflammation but also to systemic inflammation upon liver failure in rat models and cirrhotic patients. J Neuroinflammation 2015;12:183.

14. Larrinaga G, Perez I, Blanco L, et al. Increased prolyl endopeptidase activity in human neoplasia. Regul Pept 2010;163:102-6.

15. Klegeris A, Li J, Bammler TK, et al. Prolyl endopeptidase is revealed following SILAC analysis to be a novel mediator of human microglial and THP-1 cell neurotoxicity. Glia 2008;56:675-85.

16. Natunen TA, Gynther M, Rostalski H, et al. Extracellular prolyl oligopeptidase derived from activated microglia is a potential neuroprotection target. Basic Clin Pharmacol Toxicol 2019;124:40-9.

17. Zhou D, Li BH, Wang J, et al. Prolyl Oligopeptidase Inhibition Attenuates Steatosis in the L02 Human Liver Cell Line. PLoS One 2016;11:e0165224.

18. Jiang DX, Zhang JB, Li MT, et al. Prolyl endopeptidase gene disruption attenuates high fat diet-induced nonalcoholic fatty liver disease in mice by improving hepatic steatosis and inflammation. Ann Transl Med 2020;8:218.

19. Tenorio-Laranga J, Mannisto PT, Storvik M, et al. Fourday inhibition of prolyl oligopeptidase causes significant changes in the peptidome of rat brain, liver and kidney. Biochimie 2012;94:1849-59.

20. Moreno-Baylach MJ, Puttonen KA, Tenorio-Laranga J, et al. Prolyl endopeptidase is involved in cellular signalling in human neuroblastoma SH-SY5Y cells. Neurosignals 2011;19:97-109.

21. Höfling C, Kulesskaya N, Jaako K, et al. Deficiency of prolyl oligopeptidase in mice disturbs synaptic plasticity and reduces anxiety-like behaviour, body weight, and brain volume. Eur Neuropsychopharmacol 2016;26:1048-61.

22. Theocharis AD, Manou D, Karamanos NK. The extracellular matrix as a multitasking player in disease. FEBS J 2019;286:2830-69.

23. Hahn CS, Scott DW, Xu X, et al. The matrikine N- $\alpha$-PGP couples extracellular matrix fragmentation to endothelial permeability. Sci Adv 2015;1:e1500175.

Cite this article as: García-Horsman JA. The role of prolyl oligopeptidase, understanding the puzzle. Ann Transl Med 2020;8(16):983. doi: 10.21037/atm-20-3412 